\title{
Absolute, relative and intrinsic rock brittleness at compression
}

\author{
B.G. Tarasov Centre for Offshore Foundation Systems, The University of Western Australia, Australia \\ Y. Potvin Australian Centre for Geomechanics, The University of Western Australia, Australia
}

\begin{abstract}
Many brittleness criteria have been proposed to characterise material behaviour under triaxial compression, but there is no consensus as to which criteria is the most suitable. It was shown recently that increasing $\sigma_{3}$ can lead to contradictory intact rock behaviour within different ranges of $\sigma_{3}$. For example, rock behaviour can be changed from Class I (ductile) to Class II (brittle) and then to Class I again, based on the Wawersik and Fairhurst (1970) classification. Brittleness in this case can vary from absolute brittleness to absolute ductility. In this paper, it is argued that only two of the many existing criteria can properly describe the variation of brittleness within a wide range of confinements. These criteria rely upon energy balance and are based on sound physics principles.
\end{abstract}

\section{Introduction}

Brittleness is a very important mechanical property of intact rock because it has a strong influence on the failure process and on the rock mass response to mining or tunnelling activities. However, the concept of brittleness in rock mechanics is yet to be precisely defined. Several brittleness criteria have been proposed to characterise material behaviour under compression (Andreev, 1995; Baron et al., 1962; Batougina et al., 1983; Bergman and Still, 1983; Beron et al., 1983; Coates, 1966; Hajiabdolmajid et al., 2003; He et al., 1990; Hucka and Das, 1974; Kidybinski, 1981; Manjikov et al., 1983; Petoukhov and Linkov, 1983; Recommendation, 1988; Stavrogin and Protossenia, 1985; Tarasov, 2010, 2011; Tarasov and Randolph, 2011; Vardoulakis, 1984; Walsh and Brace, 1964). Difficulties in reaching a consensus can be explained by the existence of two alternative failure mechanisms, tensile and shear fracturing, taking place under different compressive loading conditions. Also brittleness can be treated in two ways; as an intrinsic material property, or as the material behaviour under an external loading system contributing additional energy to the failure process.

Large seismic events are often produced when rock masses are submitted to triaxial compression generating violent shear failures. The correct determination of brittleness at such loading conditions is important to better understand these dynamic events. Unlike the generally accepted idea that rising confining pressure $\sigma_{3}$ makes rocks less brittle, the reality is more complex. Recently published papers (Tarasov, 2010, 2011; Tarasov and Randolph, 2011) showed that an increase in $\sigma_{3}$ can lead to contradictory rock behaviour within different ranges of $\sigma_{3}$. In fact, rock behaviour can be changed from Class I (ductile) to Class II (brittle) and then to Class I again with brittleness variation from absolute brittleness to absolute ductility. In this paper, it will be shown that only two of the many existing criteria can properly describe the variation of brittleness within the whole range of testing conditions. These criteria rely upon energy balance and are based on sound physics principles.

\section{Brief analysis of brittleness criteria}

Rock brittleness is determined by different parameters obtained experimentally. These parameters can represent intrinsic material properties and also the loading conditions (e.g. the stiffness or elastic energy of the loading system). Brittleness indexes involving solely intrinsic parameters characterise the intrinsic material brittleness. Brittleness indexes based on ratios involving both intrinsic material parameters and 
loading system parameters, characterise material behaviour in relation to the loading conditions. For the purpose of this discussion these indexes are called relative material brittleness. The present paper focuses mainly on criteria characterising intrinsic rock brittleness.

a)

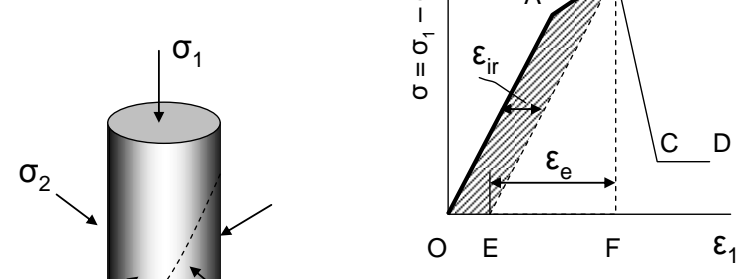

c)

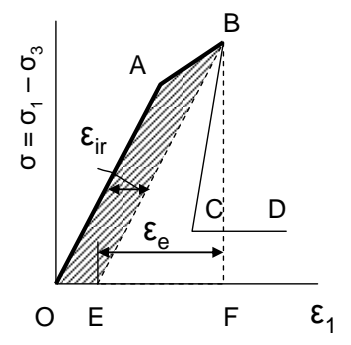

Class I

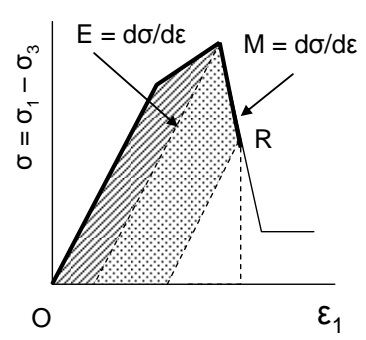

Class II

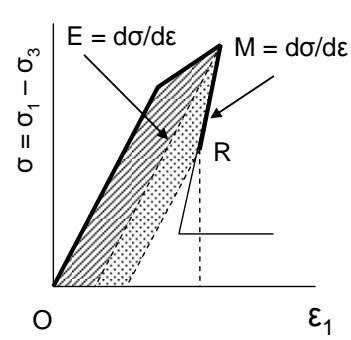

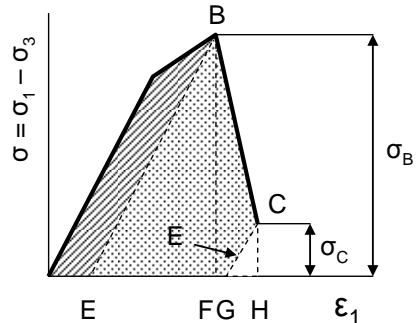



Figure 1 a) Schema of a specimen loading at triaxial compression; b) Energy balance at rock deformation in the case of Class I behaviour; c) Energy balance at rock deformation in the case of Class II behaviour

Informative characteristics of intrinsic material properties, before and after the peak stress is reached, can be obtained from the complete stress-strain diagrams (see Figure 1). A sketch of a rock specimen, with a potential shear fracture, loaded under triaxial compression is shown in Figure 1(a). The complete stressstrain curves through OABCD (Figures 1(b) and 1(c)) illustrate two types of rock behaviour in the post-peak region: Class I and Class II according to the classification proposed by Wawersik and Fairhurst (1970). The graphs show the energy balance at three stages of deformation: at the peak stress (point $B$ ), at an intermediate post-peak stage (point R), and at the complete failure (point $\mathrm{C}$ ). The hatched area OABE defined by the sloping lines represent the pre-peak rupture energy $W_{b r}$ spent to produce irreversible deformation $\varepsilon_{i r}$ of the sample, before the peak stress is reached. The areas represented by white triangles delineated by the dotted lines correspond to elastic energy stored within the specimen body at the three mentioned stages of deformation. The area EBF corresponds to the elastic energy accumulated within the specimen material at the peak stress. The grey areas represent the post-peak rupture energy spent during the generation of the shear fracture.

The graphs illustrate the dynamics of transformation of the elastic energy accumulated within the specimen material at peak stress into the post-peak rupture energy. The white areas delineated by the dotted triangles (stored elastic energy) are replaced in the graphs by the grey areas (rupture energy). The stored elastic energy represents the source of the post-peak failure process and provides the physical basis for the post-peak failure regime. For Class II, the shear fracture development occurs entirely due to the elastic energy available from the material. The failure process has a self-sustaining character with the release of excess energy corresponding to area HCBF (note that the small white dotted triangle GCH represents the unconsumed portion of the stored elastic energy after failure). The release of the excess energy can be transformed into the failure process dynamics, i.e. kinetic energy of flying fragments, seismic energy, fragmentation, heat, etc. For Class I, the elastic energy available from the material is entirely consumed by the rupture process, and some additional amount of energy (area FBCG) is required to support this process. 
Brittleness indexes based upon the ratio between the elastic energy and the post-peak rupture energy (or released energy) can be used to characterise the capability of the rock for self-sustaining failure due to the elastic energy available from the material. Such brittleness indexes actually characterise the degree of intrinsic instability of the material at failure. The graphs in Figure 1 can therefore be used to determine brittleness from energy parameters. For a simplified estimation of the elastic energy $\mathrm{dW}_{\mathrm{e}}$ withdrawn from the material specimen during the post-peak failure process between points $B$ and $C$, it is assumed that the elastic modulus $E=d \sigma / d \varepsilon$ is the same at both points. It should be noted that the modulus $E$ represents the unloading elastic modulus.

$$
d W_{e}=\frac{\sigma_{B}^{2}-\sigma_{C}^{2}}{2 E}
$$

The graphs show that the post-peak rupture energy $\mathrm{dW}_{\mathrm{r}}$ (grey area) is determined by the amount of withdrawn elastic energy $d W_{e}$ plus the additional energy corresponding to area FBCG in the case of Class I behaviour, or minus the excess released elastic energy corresponding to area HCBF in the case of Class II behaviour. The excess (or released) energy is described by Equation (2).

$$
d W_{a}=\frac{\sigma_{B}^{2}-\sigma_{C}^{2}}{2 M}
$$

Here $M=d \sigma / d \varepsilon$ is the post-peak modulus. $M$ is negative for Class I and positive for Class II behaviour.

The post-peak rupture energy $\mathrm{dW}_{\mathrm{r}}$ is described by Equation (3). The equation takes into account the sign of post-peak modulus $\mathrm{M}$ for Class I and Class II behaviour:

$$
d W_{r}=d W_{e}-d W_{a}=\frac{\left(\sigma_{B}^{2}-\sigma_{C}^{2}\right)(M-E)}{2 E M}
$$

The brittleness index $\mathrm{K}_{1}$ below is determined by the ratio between the post-peak rupture energy and the withdrawn elastic energy (Tarasov, 2010, 2011; Tarasov and Randolph, 2011):

$$
K_{1}=\frac{d W_{r}}{d W_{e}}=\frac{M-E}{M}
$$

The brittleness index $\mathrm{K}_{2}$ represents the ratio between the excess (released) and the withdrawn elastic energy (Tarasov, 2010, 2011; Tarasov and Randolph, 2011):

$$
K_{2}=\frac{d W_{a}}{d W_{e}}=\frac{E}{M}
$$

It is known that the unloading elastic modulus $E$ and the post-peak modulus $M$ can vary significantly with the fracture development. However, two infinitely near points located on a post-peak curve (for example points $B$ and $C$ in Figure 2) can be characterised by the same value of $E$. The corresponding modulus $M$ is determined on the basis of a tangent line. Increments of withdrawn elastic energy $\mathrm{dW}_{\mathrm{e}}$, post-peak rupture energy $d W_{r}$, and excess (released) energy $d W_{a}$ associated with fracture development between the neighbouring points $B$ and $C$ are described precisely by Equations (1), (2) and (3). Using Equations (4) and (5), brittleness indexes $K_{1}$ and $K_{2}$ can be determined for any stage of the post-peak process. 


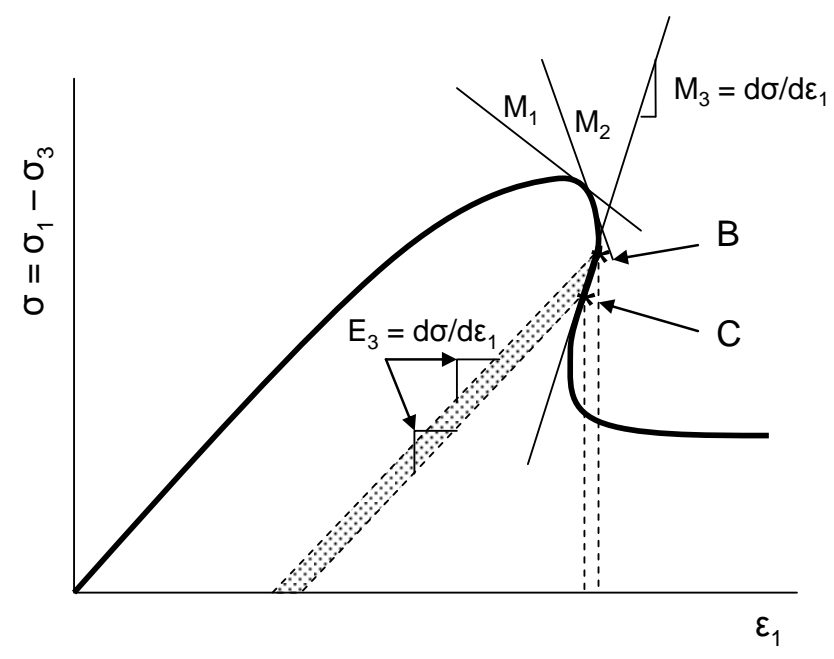

Figure 2 Illustration of local brittleness estimation by brittleness indexes $K_{1}$ and $K_{2}$

Brittleness indexes $K_{1}$ and $K_{2}$ characterise unambiguously the rock brittleness at different loading conditions. Figure 3 shows scales of rock brittleness indexes $K_{1}$ and $K_{2}$ with brittleness increasing from left to right (Tarasov, 2010, 2011; Tarasov and Randolph, 2011). The complete curves (differential stress $\sigma$ versus axial strain $\varepsilon_{1}$ ) illustrate how the different curve shapes describe a variation in brittleness. It is assumed, for simplicity, that the pre-peak parts of the curves are the same. Areas defined by the large dotted triangles correspond to elastic energy $W_{\mathrm{e}}$ stored within the rock material at the peak stress, while the smaller white triangles on the right side of the curves represent the unconsumed portion of the stored elastic energy, within the material, after failure. The post-peak parts of the curves, which are characterised by the post-peak modulus $\mathrm{M}$, are different for each curve. The grey areas represent the post-peak rupture energy $d W_{r}$ associated with strength degradation at failure from the peak stress to the residual strength (horizontal part of the post-peak curves).

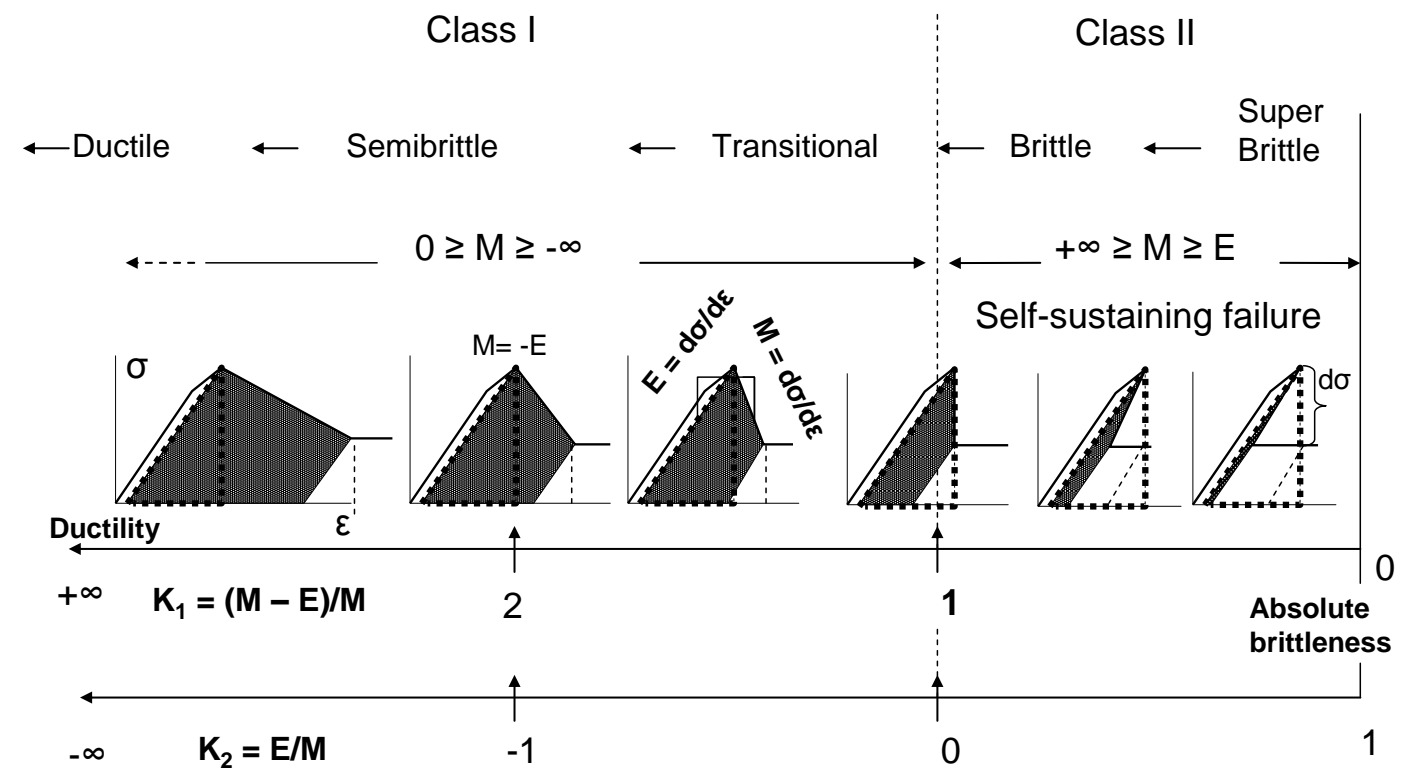

Figure 3 Scale of brittleness indexes $K_{1}$ and $K_{2}$ with characteristic shapes of complete stress-strain curves (Tarasov, 2010, 2011; Tarasov and Randolph, 2011)

Figure 3 shows variation in brittleness from absolute brittleness to ductility if read from right to left. The absolute brittleness has the following characteristics and parameters:

- The post-peak modulus is the same as the elastic modulus $\mathrm{M}=\mathrm{E}$. 
- There is no portion of the stored energy transformed into post-peak rupture energy $\mathrm{dW}_{\mathrm{r}}=0$.

- The withdrawn elastic energy is entirely transformed into excess energy $d W_{e}=d W_{a}$.

- $\mathrm{K}_{1}=0$.

- $\mathrm{K}_{2}=1$.

Within the range of brittleness indexes $1>K_{1}>0$ and $0<K_{2}<1$ the elastic energy $d W_{e}$ withdrawn from the specimen material during stress degradation on the value $d \sigma$ exceeds the corresponding rupture energy $\mathrm{dW}_{\mathrm{r}}$, leading to self-sustaining failure (brittle Class II behaviour). The self-sustaining failure normally has a spontaneous character even for a hypothetically perfectly stiff testing machine. The greater the difference between $\mathrm{dW}_{\mathrm{e}}$ and $\mathrm{dW}_{\mathrm{r}}$ the closer the material behaviour is to absolute brittleness and the more violent is the self-sustaining failure. It should be noted that the use of very stiff and servo-controlled loading machines allow in many cases controllable failure for rocks characterised by the positive post-peak modulus $M$ due to the extraction of the excess elastic energy from the material body. For the range of brittleness indexes $+\infty>K_{1}>1$ and $-\infty<K_{2}<0$ the rupture development is not self-sustaining (Class I behaviour). Variation in failure regimes corresponding to an increase in the rock brittleness is indicated in the upper part of Figure 4. These regimes are: ductile, semi-brittle, transitional, brittle and super-brittle. The characteristic features of the super-brittle regime are further discussed.

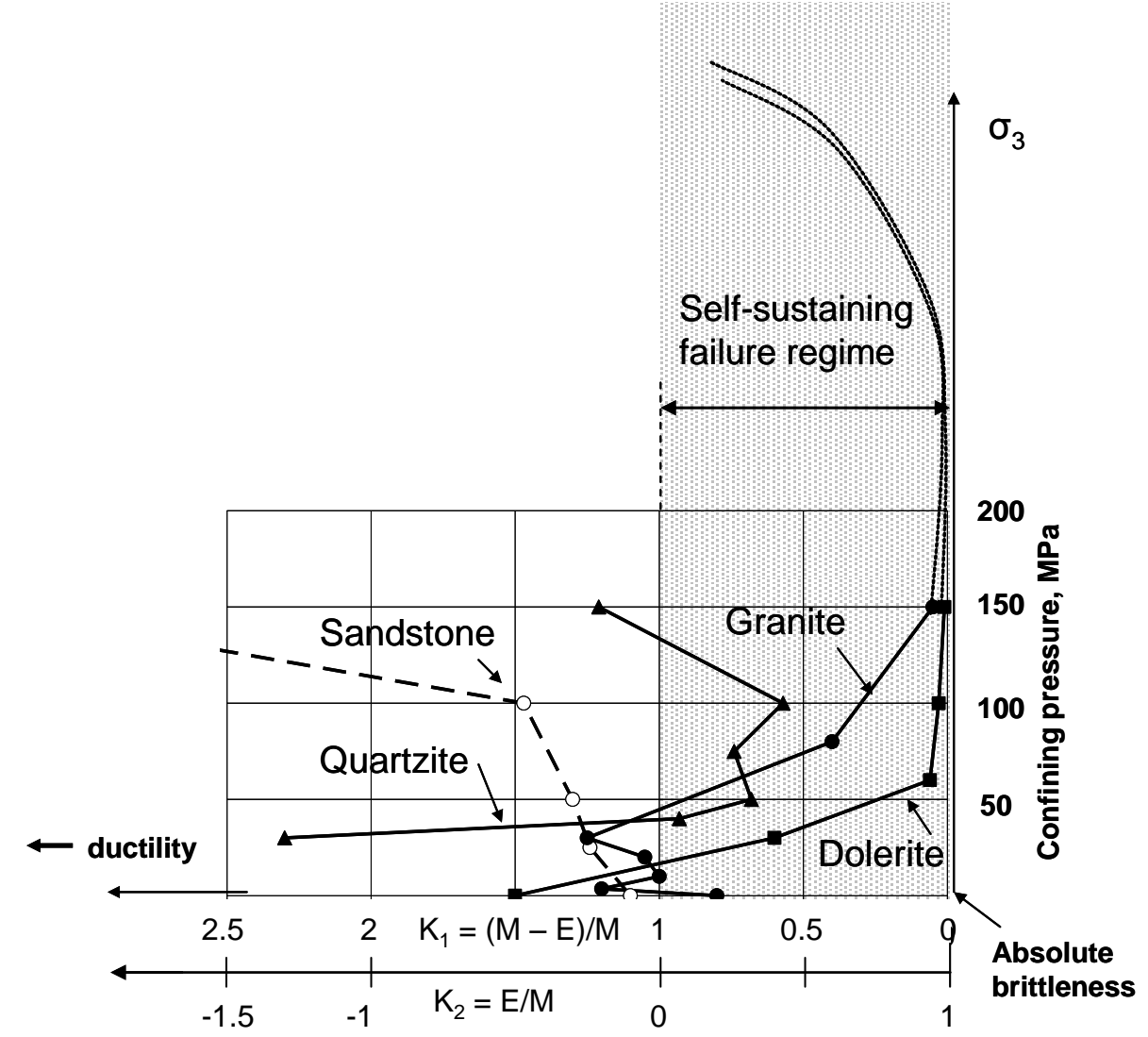

Figure 4 Variation of brittleness indexes $K_{1}$ and $K_{2}$ versus confining pressure $\sigma_{3}$ for rocks of different hardness (modified from Tarasov, 2010, 2011; Tarasov and Randolph, 2011)

Figure 4 shows the variation of brittleness index $K_{1}$ and $K_{2}$ for four rocks exhibiting different responses to rising confining pressure $\sigma_{3}$ (Tarasov, 2010, 2011; Tarasov and Randolph, 2011). The self-sustaining failure regime corresponds to $1>K_{1}>0$ and $0<K_{2}<1$. The sandstone curve indicates that an increase in confinement $\sigma_{3}$ makes the rock less brittle. This behaviour is typical for softer rocks. For the quartzite, increase in confinement $\sigma_{3}$ within the range of 0-100 MPa makes the material more brittle. At greater confinement the brittleness decreases. For the granite, increase in $\sigma_{3}$ within the range of 0-30 MPa makes 
it less brittle. When $\sigma_{3}>30 \mathrm{MPa}$, the brittleness increases dramatically. The dolerite curve also shows very severe rock embrittlement. At $\sigma_{3}=75 \mathrm{MPa}$, according to the brittleness index $\mathrm{K}_{1}$, the dolerite became 250 times more brittle when compared to uniaxial compression $\left(K_{1}(0)=1.5 ; K_{1}(75)=0.006\right)$. At $\sigma_{3}=100$ and $150 \mathrm{MPa}$ the brittleness increased significantly, further approaching absolute brittleness. The dotted lines indicate the expected brittleness variation for granite and dolerite at greater values of $\sigma_{3}$ : the brittleness continues to increase until it reaches a maximum at some level of $\sigma_{3}$ and then decreases, as all rocks become ductile at very high confining stresses. It is estimated (Tarasov, 2010, 2011; Tarasov and Randolph, 2011 ) that the maximum brittleness for granite is reached at $\sigma_{3} \approx 300 \mathrm{MPa}$. For rocks that are as hard as quartzite, the mode of brittleness variation is similar, but the maximum brittleness is lower and the range of confining pressure where embrittlement takes place is smaller.

Brittleness indexes similar to $K_{1}$ and $K_{2}$ were proposed earlier in (Batougina et al., 1983; Stavrogin and Protossenia, 1985; Petoukhov and Linkov, 1983; Manjikov et al., 1983; Bergman and Still, 1983):

$$
\begin{gathered}
k_{3}=\frac{M}{E+M} \\
k_{4}=\frac{M}{E}
\end{gathered}
$$

However, the brittleness indexes $k_{3}$ and $k_{4}$ include some uncertainties which can lead to conflicting results for estimating the brittleness at different loading conditions. Also these indexes do not allow the creation of continuous and unambiguous scale of brittleness similar to the one presented in Figures 3 and 4 . Scales of brittleness for $k_{3}$ and $k_{4}$ are stretched between $k=-\infty$ and $k=+\infty$, and the extreme points of each scale $(-\infty$ and $+\infty)$ are characterised by the same shape of stress-strain curves. Other zones of discontinuity are located in a central part of the scales between conditions of the absolute brittleness $\left(k_{3}=0.5\right.$ and $\left.k_{4}=1\right)$ and absolute ductility $\left(k_{3}=0\right.$ and $\left.k_{4}=0\right)$. Hence, the brittleness indexes $k_{3}$ and $k_{4}$ are not ideal for brittleness characterisation at different levels of confining pressure.

Brittleness indexes representing ratios of different combination between pre-peak and post-peak strain $\left(k_{5}\right.$ and $k_{6}$, Equations (8) and (9)) were discussed in other publications (Andreev, 1995; Recommendation 1988; He et al., 1990). Note that $\varepsilon_{\mathrm{e}}$ is the elastic strain, $\varepsilon_{\mathrm{p}}$ is the post-peak strain and $\varepsilon_{\mathrm{tp}}$ is the total irreversible post-peak strain.

$$
\begin{aligned}
& k_{5}=\frac{\varepsilon_{p}}{\varepsilon_{e}} \\
& k_{6}=\frac{\varepsilon_{t p}}{\varepsilon_{e}}
\end{aligned}
$$

It is found that these strain based indexes also give ambiguous results when used to characterise the brittleness. For example, three stress-strain curves in Figure 5 have the same elastic modulus $E$. At some stages of post-peak deformation, they have a very different post-peak modulus $M$, which suggests very different brittleness. However, brittleness indexes $k_{5}$ and $k_{6}$ based on ratios between values of elastic and post-peak deformations determined at a stage shown in Figure 5 have the same value for all three rocks. 

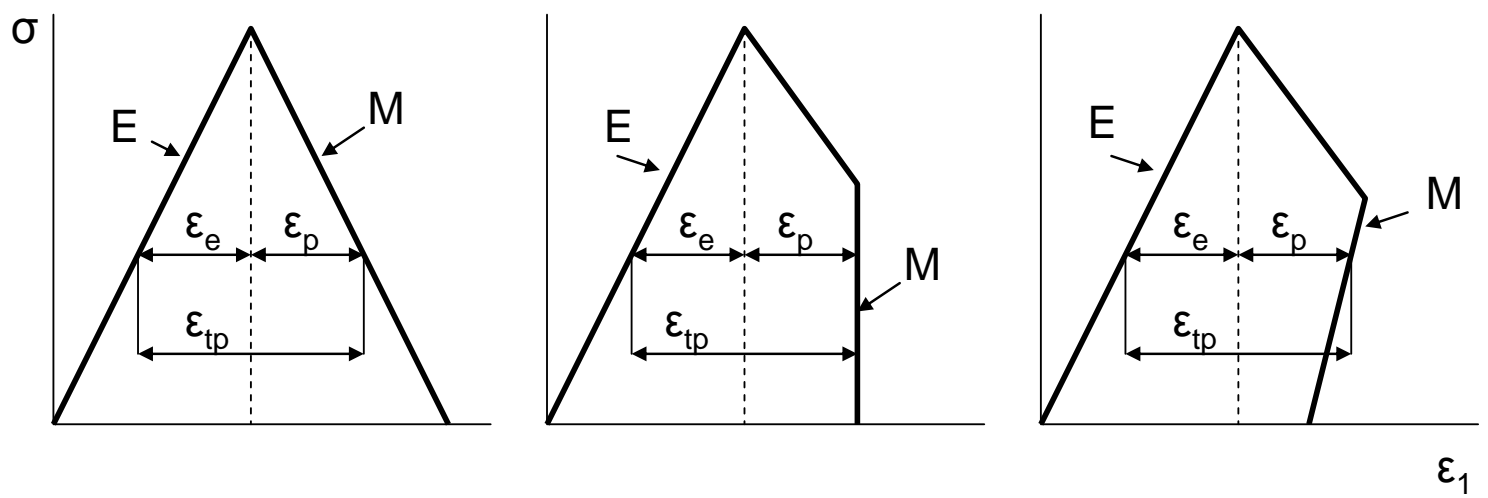

Figure 5 Schema for estimation of rock brittleness from elastic and post-peak deformations

Brittleness indexes based on different combinations of other parameters may give conflicting results at different loading conditions because unlike $\mathrm{K}_{1}$ and $\mathrm{K}_{2}$, they do not have any physical foundation. A number of examples are discussed below.

Brittleness indexes involving parameters associated with the pre-peak irreversible deformation $\left(\mathrm{k}_{7}, \mathrm{k}_{8}\right.$, and k9) have also been proposed (Coates, 1966; Hucka and Das, 1974; Baron et al., 1962; Kidybinski, 1981).

$$
\begin{gathered}
k_{7}=\frac{\varepsilon_{e}}{\varepsilon_{i r}+\varepsilon_{e}} \\
k_{8}=\frac{W_{e}}{W_{i r}+W_{e}} \\
k_{9}=\frac{W_{i r}}{W_{e}}
\end{gathered}
$$

However, experimental studies have shown that the value of the pre-peak irreversible deformation $\varepsilon_{\text {ir }}$ and the corresponding energy $W_{b r}$ (see Figure 1 ) do not correlate with post-peak rock properties. The graphs in Figure 1 show that the same pre-peak irreversible behaviour can be followed by both Class I and Class II behaviour in the post-peak region. Furthermore, increase in confinement $\left(\sigma_{3}\right)$ causing increase in pre-peak ductility can lead to both an increase or decrease in post-peak ductility.

The determination of intrinsic material brittleness from compressive $R_{c}$ and tensile $R_{t}$ strengths indexes, e.g. $k_{10}=R_{c} / R_{t}$ (Beron et al., 1983; Walsh and Brace, 1964; Vardoulakis, 1984) gives conflicting results when samples are tested under triaxial compression. It is accepted that the difference between $R_{c}$ and $R_{t}$ increases with an increase in brittleness. However, at greater confinement $\left(\sigma_{3}\right)$, despite the fact that the compressive strength $R_{c}$ increases the material behaviour can be accompanied by both increase and decrease in material brittleness as shown in Figure 4. Determination of brittleness $k_{11}$ from Mohr's Envelope (Hucka and Das, 1974) implies the decrease in brittleness with rising confining pressure $\sigma_{3}$ and cannot reflect rock embrittlement within a certain range of high confining stress $\left(\sigma_{3}\right)$.

\section{Failure mechanisms providing high (Class I) and low (Class II) rupture energy}

Figure 6(a) shows four stages of shear rupture development in a specimen when submitted to triaxial compression. A load cell and an axial gauge mounted on the specimen are used to measure the average load bearing capacity and the strain of the specimen during the post-peak stage of the loading procedure. The real shear resistance and displacement along the future failure plane are very non-uniform. Three specific zones can be distinguished (see Figure 6(a-ii)): (1) the process zone (or rupture head) where the 
failure process is in progress; (2) the core frictional zone located behind the head where the full friction is mobilised, and (3) the intact zone in front of the head where the resistance is determined by the cohesive strength. With fracture propagation the cohesive strength of decreasing zone (3) is substituted by the frictional resistance of increasing zone (2). This process is accompanied by the decrease in bearing capacity of the specimen from the cohesive strength to the frictional (residual) strength. The fracture mechanism operating within the head (process) zone (1) plays the key role in the character of transformation from the cohesive to frictional strength.

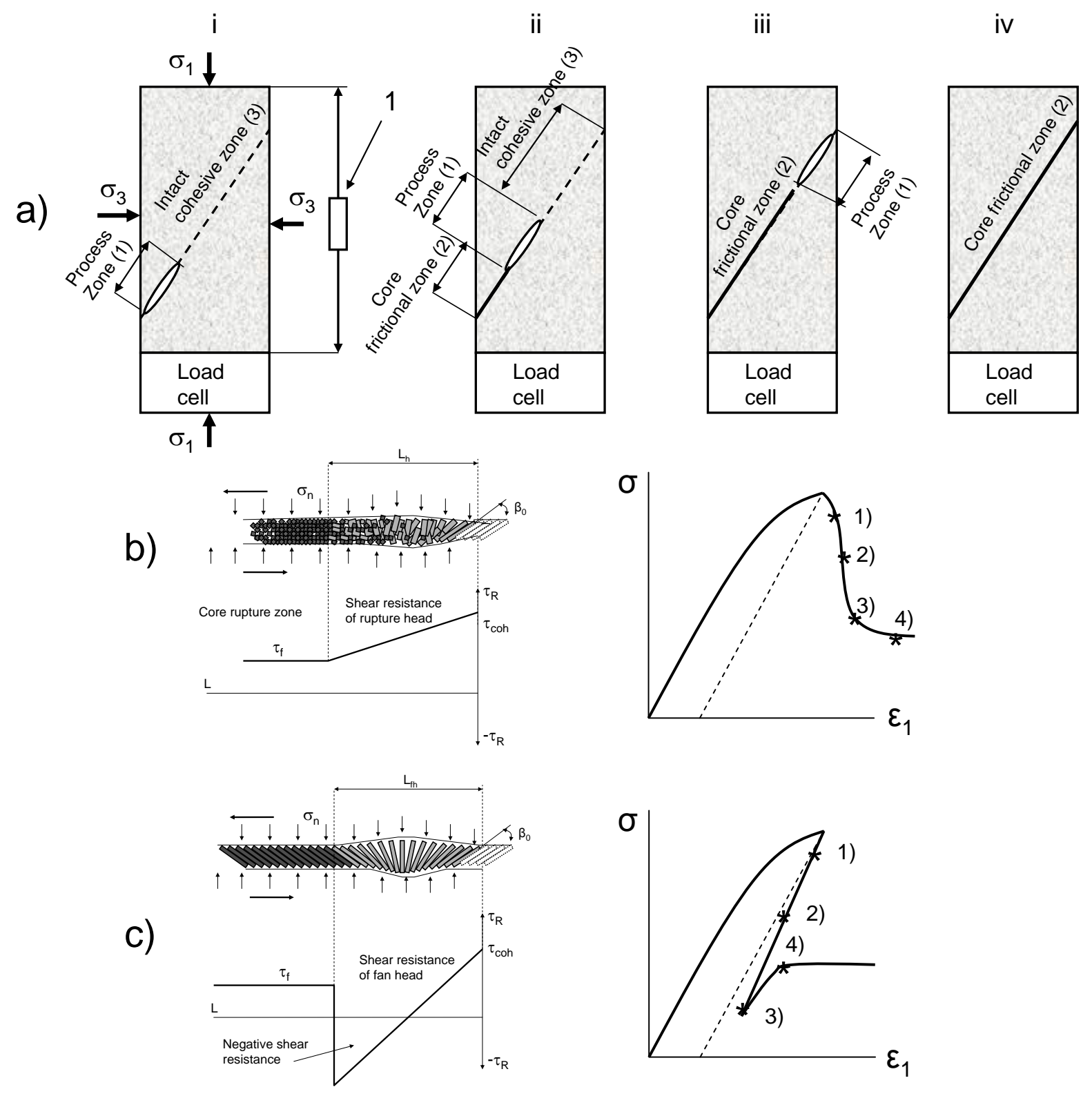

Figure 6 a) Four stages of shear rupture development in a specimen at triaxial compression; b) Frictional; and c) Frictionless concepts of shear fracture development

It is known that a shear rupture can propagate in its own plane due to the creation of short tensile cracks in front of the rupture tips (Reches, 1999; Cox and Scholz, 1988; Reches and Lockner, 1994). This forms the universal structure of shear ruptures represented by an echelon of blocks (or slabs) separated by tensile cracks - known as 'book-shelf' structure (Reches, 1999; Cox and Scholz, 1988; Reches and Lockner, 1994; Peng and Johnson, 1972; King and Sammis, 1992) or Ortlepp shears (Van Aswegen, 2008; Ortlepp, 1997). The initial angle $\beta_{0}$ of the tensile crack and block inclination to the shear rupture plane is about $30-40^{\circ}$ (Horii and Nemat-Nasser, 1985). Shear displacement along the fault causes rotation of the blocks of the 
'book-shelf' structure between the rupture surfaces (Cox and Scholz, 1988; Reches and Lockner, 1994; Peng and Johnson, 1972; King and Sammis, 1992; Tarasov, 2010, 2011; Tarasov and Randolph, 2011).

Figure $6(\mathrm{~b})$ illustrates the essence of the shear rupture mechanism providing large rupture energy. Blocks located in the front part of the head create significant resistance to shear; however, they collapse with rotation providing gradual transformation of shear resistance within the head zone from cohesive to frictional levels. A graph under the shear rupture in Figure $6(\mathrm{~b})$ shows the shear resistance variation along the fault head. The crushing and comminution of blocks within the head zone can absorb large amounts of energy. This is expected since the development of shear fractures requires displacement to occur along the total fault. This form of rupture development is classified as a crack-like mode. Such a rupture mechanism normally produces a Class I material behaviour in the post-peak region. Four points on the stress-strain curve on the right correspond to the four stages of deformation shown in Figure 6(a).

Figure 6(c) illustrates a model where rotating blocks can withstand the rotation without collapse by behaving as hinges (see details in Tarasov, 2010, 2011; Tarasov and Randolph, 2011). Due to consecutive formation and rotation of the blocks, these should form a fan structure within the rupture head. A remarkable feature of the rotating blocks (hinges) in the second half of the fan structure (where $\beta>90^{\circ}$ ) is the creation of active forces under the effect of normal stress applied. A graph under the shear rupture in Figure $6(\mathrm{c})$ shows the shear resistance variation along the fault head. The bottom part of the graph represents active forces (negative resistance) acting in the second half of the head and assisting the fault displacement. In the core zone represented by blocks that have completed their rotation the normal residual friction is restored.

The fan structure represents a self-equilibrating mechanism and can move spontaneously as a wave with very small shear resistance. In the idealised fan-head model, the resistance to rupture propagation is determined only by the tensile strength of the material associated with consecutive formation of blocks in front of the propagating rupture. It is important that the fan-head can propagate independently of the core zone, which can remain immobile due to high frictional resistance. Hence, this mechanism creates conditions for a pulse-like mode of fracture propagation. In this situation the rupture energy is determined by shear resistance of the fan head only. The fan-head rupture mechanism represents the most energy efficient shear rupture mechanism.

This mechanism is responsible for Class II behaviour with extremely small rupture energy approaching absolute brittleness. The stress-strain curve in Figure 6(c) shows that at stage 3 of the fracture propagation, the bearing capacity of the specimen can be less than at stage 4 . It is because the shear resistance of the head (process) zone can be close to zero, decreasing the bearing capacity of the specimen. The longer the relative rupture head (process zone (1)) is, the smaller the shear resistance at stage 3 of the rupture propagation. The full frictional resistance is mobilised at stage 4 after the head completely propagates through the specimen.

The examples discussed show that shear rupture mechanisms involving the book-shelf structure can be responsible for the delay in friction mobilisation at failure. A concept of strain-dependent mobilisation of strength at failure on the basis of other failure mechanisms is discussed in (Hajiabdolmajid et al., 2003). A special strain-dependent brittleness index $k_{12}$ was introduced to consider the contribution of the cohesive and frictional strength components during the failure process. From the physical point of view the brittleness index $k_{12}$ reflects the presence of both tensile and shear mechanisms in inducing micro-cracks. This concept, however, implies an increase in ductility with rising confining pressure. Therefore, this cannot explain the very severe embrittlement observed in hard rocks under increasing confinement $\left(\sigma_{3}\right)$ and the extremely low rupture energy at high levels of $\sigma_{3}$ (see Figure 4). The reasons for rock embrittlement due to rising $\sigma_{3}$ are discussed in (Tarasov, 2010, 2011; Tarasov and Randolph, 2011) where the brittleness indexes $\mathrm{K}_{1}$ and $\mathrm{K}_{2}$ were first introduced.

Natural shear fractures can be at different stages of their development. Their shear resistance and brittleness at the post-peak failure stage can correspond symbolically to different points on the stressstrain curves shown in Figures $6(\mathrm{~b})$ and $6(\mathrm{c})$. The brittleness (degree of instability) and energy release 
during the rupture development depends on the failure stage and the rupture mechanism. The discussed brittleness indexes $\mathrm{K}_{1}$ and $\mathrm{K}_{2}$ can be used for characterisation of the stability conditions.

We should note that the proposed criteria $\mathrm{K}_{1}$ and $\mathrm{K}_{2}$ can be used for the relative stability characterisation at uniaxial compression also. In this situation, despite the fact that the failure process is associated with the development of large tensile cracks, the stability of the loading process in the post-peak region is determined by the total rupture energy and the available elastic energy characterised by the complete stress-strain curves.

\section{$4 \quad$ Relative rock brittleness and applications}

Figure 7(a) shows two generic load-displacement curves for two different rocks obtained on specimens of the same dimensions. These two rocks have the same brittleness index $K_{1}$ and $K_{2}$ because they are characterised by the same ratio between the elastic and post-peak modules: $E^{\prime}{ }_{1} / \mathrm{M}^{\prime}{ }_{1}=\mathrm{E}^{\prime}{ }_{2} / \mathrm{E}^{\prime}{ }_{2}$. However, the behaviour of these rocks during testing on the same loading system can be very different. The dotted lines on the graph characterise the stiffness $L$ of the loading system. For rock number $1, L<M^{\prime}{ }_{1}$ and in accordance with Cook (1965), failure should be unstable while for rock number 2, $L>\mathrm{M}_{2}$ and failure should be stable. On the basis of Equation (13) (Cook, 1965), the brittleness of these two rocks can be determined in relation to the loading system. Referring to the discussion in section 2 of this paper, such classification of brittleness reflects the relative brittleness of rocks instead of the intrinsic material brittleness.

$$
k_{R}=\frac{L}{M}
$$

The use of intrinsic or relative brittleness for estimation of degree of instability in practice depends on loading conditions. For instance, rock mass surrounding an extended underground excavation represents a loading system with respect to pillars supporting the excavation (see Figure 7(b)). In this case, the degree of total instability of this construction can be characterised by index $k_{R}$ representing relative brittleness. In the case of shear fracture propagation within intact rock mass (Figure $7(c)$ ) the use of intrinsic brittleness indexes $\mathrm{K}_{1}$ and $\mathrm{K}_{2}$ are more appropriate.

a)

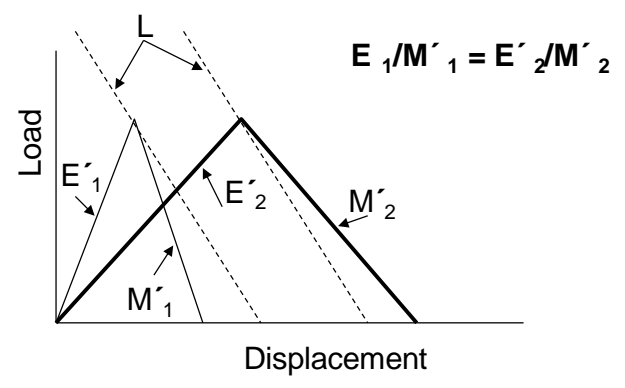

b)

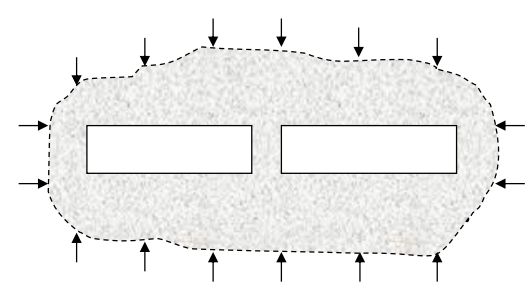

c)

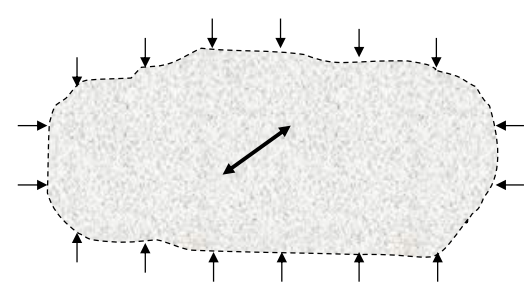

Figure 7 a) Load-displacement curves for two rocks having the same intrinsic and different relative brittleness; b) Rock mass involving an underground excavation with a pillar; c) Rock mass involving a shear fracture 
The applicability of various criteria for assessing rock brittleness under triaxial compression has been analysed. It is shown that only two of many existing criteria can properly describe the intrinsic material brittleness within the whole range of brittleness variation from the absolute brittleness to ductility. These criteria are based upon the balance between elastic energy accumulated within the material specimen and two forms of post-peak energy associated with the failure process: the rupture energy and the excess (released) energy. The brittleness indexes based on the ratio between these parameters allow for the representation of the two classes of rock behaviour (Class I and Class II) in the form of continuous, monotonic and unambiguous scale of brittleness. Other existing criteria do not provide unambiguous characterisation of rock brittleness at different loading conditions under triaxial compression.

\section{Acknow l edgements}

This work has been supported by the Centre for Offshore Foundation Systems (COFS) at The University of Western Australia, which was established under the Australian Research Council's Special Research Centre scheme and is now supported by the State Government of Western Australia through the Centre of Excellence in Science and Innovation program. This support is gratefully acknowledged.

\section{References}

Andreev, G.E. (1995) Brittle failure of rock materials, Rotterdam, Balkema, $446 \mathrm{p}$.

Baron, L.I., Loguntsov, B.M. and Posin, I.Z. (1962) Determination of rock properties, Moscow, NTILGD, 62 p.

Batougina, I.M., Petoukhov, I.M., Vinokur, B.S., Smirnov, V.A. and Rabota, E.N. (1983) Methodological instructions for rockburst prophylaxis accounting the deposit geodynamics, Leningrad, VNIMI, $80 \mathrm{p}$.

Bergman, S.G.A. and Still, H. (1983) Rockburst problems in a 2.6 million $\mathrm{m}^{3}$ underground crude oil storage in granite, in Proceedings 5th Congress ISRM, D302-D309.

Beron, A.I., Vatolin, E.S., Koifman, M.I., Mohnachev, M.P. and Chirkov, S.E. (1983) Rock properties under different loading regimes, Moscow, Nedra 120 p.

Coates, D.F. (1966) Experimental criteria for classification of rock substances, International Journal of Rock Mechanics and Mining Sciences, Vol. 3, pp. 181-189.

Cook, N.G.W. (1965) The failure of rock, International Journal of Rock Mechanics and Mining Sciences, Vol. 2, pp. 389-403.

Cox, S.J.D. and Scholz, C.H. (1988) On the formation and growth of faults: an experimental study, Journal of Structural Geology, Vol. 10, pp. 413-430.

Hajiabdolmajid, V., Kaiser, P. and Martin, C.D. (2003) Mobilised strength components in brittle failure of rock, Geotechnique, Vol. 53, No. 3, pp. 327-336.

He, C., Okubo, S. and Nishimatsu, Y. (1990) A study on the class II behaviour of rock, Rock Mechanics and Rock Engineering, Vol. 23, pp. 261-273.

Horii, H. and Nemat-Nasser, S. (1985) Compression-induced microcrack growth in brittle solids: Axial splitting and shear failure, Journal of Geophysical Research, Vol. 90, pp. 3105-3125.

Hucka, V. and Das, B. (1974) Brittleness determination of rocks by different methods, International Journal of Rock Mechanics and Mining Sciences, Vol. 11, pp. 389-392.

Kidybinski, A. (1981) Bursting liability indexes of coal, International Journal of Rock Mechanics and Mining Sciences, Vol. 18, pp. 295-304.

King, G.C.P. and Sammis, C.G. (1992) The mechanisms of finite brittle strain, PAGEOPH, Vol. 138, No. 4, pp. 611-640.

Manjikov, B.T., Mansourov, V.A., Pougacheva, T.N. and Tileguenov, K.T. (1983) Laboratory estimation of rockbursting danger, SSDRRMODMA, Frounze, llim, pp. 106-116.

Ortlepp, W.D. (1997) Rock fracture and rockbursts. SAIMM, Johannesburg, 98 p.

Peng, S. and Johnson, A.M. (1972) Crack growth and faulting in cylindrical specimens of Chelmsford granite, International Journal of Rock Mechanics and Mining Sciences, Vol. 9, pp. 37-86.

Petoukhov, I.M. and Linkov, A.M. (1983) Mechanics of rockburst and outburst, Moscow, Nedra, 298 p.

Reches, Z. (1999) Mechanisms of slip nucleation during earthquakes, EPSL, Vol. 170, pp. 475-486.

Reches, Z. and Lockner, D.A. (1994) Nucleation and growth of faults in brittle rocks, Journal of Geophysical Research, Vol. 99, No. B9, pp. 18159-18173.

Recommendation (1998) Recommendation for determining the total Mohr strength envelope and deformability for rock Leningrad, VNIMI, $102 \mathrm{p}$.

Stavrogin, A.N. and Protossenia, A.G. (1985) Rock strength and excavation stability in great depth, Moscow, Nedra, 280 p.

Tarasov, B.G. (2010) Superbrittleness of rocks at high confining pressure, in Proceedings Fifth International Seminar on Deep and High Stress Mining (Deep Mining 2010), M. Van Sint Jan and Y. Potvin (eds), 6-8 October 2010, Santiago, Chile, Australian Centre for Geomechanics, Perth, pp. 119-133. 
Tarasov, B.G. (2011) Universal scale of brittleness for rocks failed at compression, in Proceedings 13th International Conference of the International Association for Computer Methods and Advances in Geomechanics, pp. 669-673.

Tarasov, B.G. and Randolph, M.F. (2011) Superbrittleness of rocks and earthquake activity, International Journal of Rock Mechanics and Mining Sciences, Vol. 48, pp. 888-898.

Van Aswegen, G. (2008) Ortlepp shears - dynamic brittle shears of South African Gold Mines, in Proceedings First Southern Hemisphere International Rock Mechanics Symposium (SHIRMS), Y. Potvin, J. Carter, A. Dyskin and R. Jeffrey (eds), Vol. 2 Fundamental and Petroleum, 16-19 September 2009, Perth, Australia, Australian Centre for Geomechanics, Perth, pp. 111-119.

Vardoulakis, I. (1984) Rock bursting as a surface instability phenomenon, International Journal of Rock Mechanics and Mining Sciences, Vol. 21, pp. 137-144.

Walsh, J.B. and Brace, W.F. (1964) A fracture criterion for brittle anisotropic rock, Journal of Geophysical Research, Vol.69, pp. 3449-3456.

Wawersik, W.R. and Fairhurst, C. (1970) A study of brittle rock fracture in laboratory compression experiments, International Journal of Rock Mechanics and Mining Sciences, Vol. 7, pp. 561-575. 